\title{
Utilization of Polyphenyl and Polyphenyl-related Compounds by Microorganisms. Part $\mathrm{I}^{\dagger}$
}

\author{
Toshio Ohmori, Takashi IKaI, ${ }^{*}$ Yasuji Mrnoda and Koichi Yamada \\ Department of Agricultural Chemistry, Faculty of Agriculture, The University of Tokyo \\ ${ }^{*}$ Biological and Chemical Research Institute, Nissan Chemical Industry Co., Ltd.
}

Received November 27, 1972

\begin{abstract}
Two hundreds and fifty eight strains of microorganisms have been isolated from 526 samples (soil, leaf and river water gathered from 17 prefectures) by repeating liquid enrichment culture techniques in the medium containing biphenyl, diphenylmethane, diphenylethane or terphenyl, as the sole source of carbon.

In the course of investigation, several strains were found to produce a large amount of $\gamma$-benzoylbutyric acid from biphenyl. Furthermore these strains utilized $p$-Cl-biphenyl and produced $p$-Cl-benzoic acid in good yield.

Microorganisms obtained were almost short rod, motile bacteria, and fungi were also found from the screening medium of diphenylethane.
\end{abstract}

The utilization of aromatic hydrocarbons by microorganisms has already been reported by several groups of workers. We also reported the systematic studies on the oxidation of aromatic hydrocarbons by microorganisms. ${ }^{(2)}$ However, only a few of them concern with the utilization of polyphenyl and polyphenyl-related hydrocarbons. D. Lunt and W. C. Evans ${ }^{5)}$ demonstrated that gram negative bacteria isolated from soil assimilated biphenyl and produced 2,3-dihydroxybiphenyl. They also stated that 2,3-dihydroxybiphenyl was converted into $a$-hydroxy- $\beta$-phenylmuconicsemialdehyde by a particulate fraction obtained from biphenyl grown cells, and $a$-hydroxy- $\beta$-phenylmuconicsemialdehyde was assumed to be oxidized into phenylpyruvate through some unidentified intermediates. The other work $^{6}$ was the application of biphenyl and $m$-terphenyl assimilating bacteria to microbial treatment of waste water in nuclear industry.

On the other hand, polyphenyl and polyphenyl-related compounds were closely related in chemical structure to the materials of environmental pollution, for example, PCB (polychlorobiphenyl) and DDT.

$\uparrow$ Studies on the Utilization of Hydrocarbons by Microorganisms. Part XXV.
Present study was carried out from three view points. First, the substrates used in this experiment were organic synthesized materials. So, it is interesting to know whether microorganisms utilizing these rare materials are widely distributed in natural environment or not. Second, these microorganisms are expected to produce useful raw materials for organic synthesis or biological active substances from these rare materials in large amount. Third, we already mentioned above that the substrates had very similar structure to the materials of environmental pollution. So the study of the utilization of polyphenyl and polyphenyl-related compounds will be able to apply to the control of the environmental pollution.

This report describes the results of the screening of polyphenyl and polyphenylrelated hydrocarbon assimilating microorganisms, and the identification of the products accumulated in culture broth.

\section{MATERIALS AND METHODS}

Medium. The composition of screening medium was as follows: $\mathrm{NH}_{4} \mathrm{NO}_{3} ; 4.0 \mathrm{~g}, \mathrm{KH}_{2} \mathrm{PO}_{4} ; 1.5 \mathrm{~g}$, $\mathrm{Na}_{2} \mathrm{HPO}_{4} ; 1.5 \mathrm{~g}, \mathrm{MgSO}_{4} \cdot 7 \mathrm{H}_{2} \mathrm{O} ; 5.0 \mathrm{mg} \mathrm{CaCl} \cdot 2 \mathrm{H}_{2} \mathrm{O}$; $10.0 \mathrm{mg}, \mathrm{FeSO}_{4} \cdot 7 \mathrm{H}_{2} \mathrm{O} ; 5.0 \mathrm{mg}$, yeast extract; $0.5 \mathrm{~g}$, surfactant (polyoxyethylene nonyl phenyl ether) $0.005 \%$ 
$(\mathrm{v} / \mathrm{v})$ and deionized water to make 1 liter. Initial $\mathrm{pH}$ was adjusted to $7.0 \sim 7.2 .0 .5 \sim 1.0 \%$ (wt. $/ \mathrm{v}$ ) of hydrocarbon was added as the sole source of carbon after sterilization.

Cultivation. A loopful cell grown on polyphenyl or polyphenyl-related hydrocarbon agar slant for $5 \sim 7$ days at $30^{\circ} \mathrm{C}$, was inoculated and incubated at $30^{\circ} \mathrm{C}$ on a reciprocal shaker.

The hydrocarbon agar plates were prepared by two methods.

Method 1: Immediately after the test tube containing the screening medium was autoclaved, hydrocarbon which was still liquid (except $p$-terphenyl) was dispersed into petri dishes.

Method 2: Plate agar medium without hydrocarbon were prepared by the ordinary technique, and polyphenyl and poly phenyl-related hydrocarbons were sprinkled onto them.

Slant agar media were prepared by the same methods as were used for the plate media.

Hydrocarbons. Hydrocarbons (biphenyl, diphenylmethane, diphenylethane, $o-, m^{-}, p^{-t e r p h e n y l, ~ t r a n s-}$ stilbene, $p$-Cl-biphenyl, $p$-Cl-benzoic acid) were obtained from Tokyo Chemical Industry Co., Ltd., and used without further purification. n-Paraffin (super heavy) was obtained from Nippon Mining Co., Ltd.

Thin-layer chromatography. Thin-layer chromatography of ascending techniques was employed in the detection of metabolic products. Thin-layer plate of Silicagel $G$ of $0.25 \mathrm{~mm}$ thickness were dried at $115^{\circ} \mathrm{C}$ for $40 \mathrm{~min}$. Solvent system used was as follows; benzene: dioxane; acetic acid $=90: 25: 4$ (volume ratio). The spot was visualized by ultraviolet irradiation and by sprying the developing reagent.

Determination of cell growth and acid produced. Cell growth was determined by weighing dried cell weight. The precipitate of culture broth from centrifugation contains solid residual substrate hydrocarbon and bacterial cells. But after drying at $70^{\circ} \mathrm{C}$ for $3 \mathrm{hr}$ the residual hydrocarbon vapourized completely. And after drying the residue was weighed as dried cell weight.

Acid produced was determined by colorimetric procedure. 2,4-Dinitrophenylhydrazone of the produced keto acid was extracted into $10 \% \mathrm{Na}_{2} \mathrm{CO}_{3}$ solution by liquid-liquid partition technique, and absorbance at $440 \mathrm{~m} \mu$ was measured by ShimazuSpectronic-20. The procedure is shown in Fig. 1.

Isolation of microorganisms. The enrichment culture was carried out by adding $0.05 \sim 0.1 \mathrm{~g}$ of soil samples or $0.1 \mathrm{ml}$ of the supernatant of $0.1 \mathrm{M}$ phos-

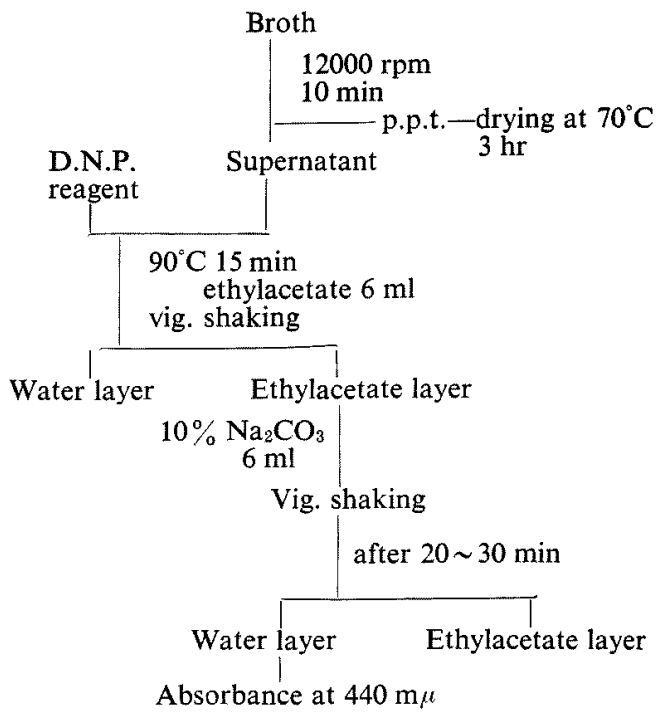

Fig. 1. The Procedure of Determination of Cell Growth and Acid Produced.

D.N.P.; Dinitrophenylhydrazine

phate buffer in which leaf, flower or vegitable samples were dipped for $2 \mathrm{hr}$, into $5 \mathrm{ml}$ liquid medium in test tube. After second enrichment culture, microorganisms were isolated on polyphenyl or polyphenylrelated hydrocarbons agar medium by the ordinary method.

Another isolation method was carried out by direct sprinkling of soil samples onto agar plate medium.

\section{RESULTS}

\section{Microorganisms}

The number of microorganisms isolated

TABle I. Microorganisms Isolated

\begin{tabular}{|c|c|c|c|}
\hline Substrate & Origin & $\begin{array}{l}\text { Number of } \\
\text { isolation } \\
\text { sources }\end{array}$ & $\begin{array}{l}\text { Number of } \\
\text { growth }\end{array}$ \\
\hline & Soil & 392 & 34 \\
\hline \multirow[t]{2}{*}{ Biphenyl } & leaf & 34 & 5 \\
\hline & total & 426 & 39 \\
\hline Diphenyl- & soil & 390 & 33 \\
\hline \multirow[t]{2}{*}{ methane } & leaf & 34 & 7 \\
\hline & total & 424 & 40 \\
\hline \multirow[t]{2}{*}{$\begin{array}{l}\text { Diphenyl- } \\
\text { ethane }\end{array}$} & $\begin{array}{l}\text { soil } \\
\text { leaf }\end{array}$ & 395 & 165 \\
\hline & total & 395 & 165 \\
\hline Terphenyl & soil & 488 & 13 \\
\hline \multirow{2}{*}{$(o-, m-, p-)}$, & leaf & 34 & 1 \\
\hline & total & 522 & 14 \\
\hline
\end{tabular}


Table II. Substrate Assimilation Specificity of Isolated Microorganisms

Microorganisms isolated from biphenyl, diphenylmethane, diphenylethane and terphenyl media are listed in group $\mathrm{A}, \mathrm{B}, \mathrm{C}$ and $\mathrm{D}$, respectively.

b.p.; biphenyl, $n$-p; $n$-paraffin, d.p.m.; diphenylmethane, d.p.e.; diphenylethane, t.p.; terphenyl, t-st; trans-stilbene, $p$-Cl-b.p.; $p$-Cl-biphenyl, + ; growth.

\begin{tabular}{|c|c|c|c|c|c|c|c|c|}
\hline \multirow{2}{*}{\multicolumn{2}{|c|}{ Slant No. }} & \multicolumn{7}{|c|}{ Substrate } \\
\hline & & $n-p$ & b.p. & d.p.m. & d.p.e. & t.p. & $\mathrm{t}$-st. & $\begin{array}{c}p-\mathrm{Cl}- \\
\text { b.p. }\end{array}$ \\
\hline \multirow{10}{*}{ A } & 52 & \multirow{5}{*}{+} & + & + & \multirow[t]{2}{*}{+} & & \multirow[t]{2}{*}{+} & \multirow{10}{*}{$\begin{array}{l}+ \\
+ \\
+\end{array}$} \\
\hline & 105 & & + & & & & & \\
\hline & 146 & & + & + & \multirow{2}{*}{\multicolumn{2}{|c|}{+}} & \multirow[t]{2}{*}{+} & \\
\hline & 267 & & + & + & & & & \\
\hline & 291 & & + & & & & & \\
\hline & 313 & & + & + & \multicolumn{2}{|l|}{+} & & \\
\hline & 334 & + & + & + & & & & \\
\hline & 364 & + & + & & & & & \\
\hline & 404 & + & + & + & & & & \\
\hline & 431 & & + & + & + & + & + & \\
\hline \multirow{5}{*}{$\mathrm{B}$} & 93 & & + & + & + & & \multirow[t]{5}{*}{+} & \\
\hline & 104 & + & + & + & + & & & \\
\hline & 326 & + & + & + & + & & & \\
\hline & 370 & + & + & + & + & & & \\
\hline & 412 & + & + & + & + & & & \\
\hline \multirow{5}{*}{$\mathrm{C}$} & 11 & + & & & + & + & \multirow{5}{*}{+} & \\
\hline & 25 & + & & & + & & & \\
\hline & 77 & + & + & + & + & & & \\
\hline & 353 & & + & + & + & & & \\
\hline & 365 & & & & + & & & \\
\hline \multirow{4}{*}{$\mathrm{D}$} & 171 & + & & & & + & \multirow{4}{*}{$\begin{array}{l}+ \\
+\end{array}$} & \\
\hline & 506 & + & & + & & + & & \\
\hline & 565 & + & & & & + & & \\
\hline & 621 & + & & & & + & & \\
\hline
\end{tabular}

are shown in Table I. Microorganisms isolated from terphenyl medium were very few, and most of them were obtained from direct sprinkling of samples of isolation source onto agar plate medium. Although 5 strains of terphenyl assimilating microorganisms showed good growth on agar plate medium, the other 9 strains seemed to grow only when inoculated into liquid medium from bouillon agar medium. The reason of this phenomenon is not yet clear.

Most of the isolated microorganisms were short rod motile bacteria. Among those from diphenylethane medium, fungi were also found. But, yeast could not be found.

Specificity of substrate assimilation
The assimilation of n-paraffin, biphenyl, diphenylmethane, diphenylethane, $o_{-}^{-}, m^{-}, p-$ terphenyl $(o-, m-, p$-terphenyl were mixed to be $1: 1: 1$ of weight ratio), trans-stilbene and p-Cl-biphenyl were tested, by observing growth on agar slant medium containing each hydrocabon.

Ten strains of microorganisms isolated from biphenyl medium, 5 strains of those from diphenylmethane, 5 strains of those from diphenylethane, 4 strains of those from terphenyl medium, we selected for growth test.

Table II shows the result of substrate specificity of microorganisms. They seem to be classified into several groups. For example most of those from terphenyl did not grow on 
1 liter Culture broth after 3 days, $30^{\circ} \mathrm{C}, 200 \mathrm{rpm}$ pH $1 \sim 2$ (dil. $\mathrm{HCl}$ )

Ether-extraction

Ether phase

$$
5 \% \mathrm{NaHCO}_{3} \text { extraction }
$$

\section{Ether phase Water phase}

$$
\begin{aligned}
& \text { EH 1 2 } \\
& \text { Ether phase } \\
& \begin{array}{l}
\text { Dehydration } \\
\text { (anhydrous } \mathrm{Na}_{2} \mathrm{SO}_{4} \text { ) } \\
\text { Evaporate in vacuo }
\end{array} \\
& \text { Crude extract } \\
& 0.515 \mathrm{~g}
\end{aligned}
$$

Fig. 2. Procedure of the Extraction of Degradation Product from Biphenyl.

biphenyl, diphenylmethane and diphenylethane. But those from biphenyl, diphenylmethane and diphenylethane, did not grow on terphenyl.

Determination of metabolic product from biphenyl

Strain S-291-B-1 isolated from biphenyl medium was cultured for $48 \mathrm{hr}$ in $50 \mathrm{ml}$ medium in $500 \mathrm{ml}$ shake flask. Then the broth was inoculated into 1 liter medium in 5 liter Erlenmeyer flask. The cultivation was carried out at $30^{\circ} \mathrm{C}$ for $72 \sim 96 \mathrm{hr}$. After that the acidic product in culture broth was extracted by ethylether, further extraction

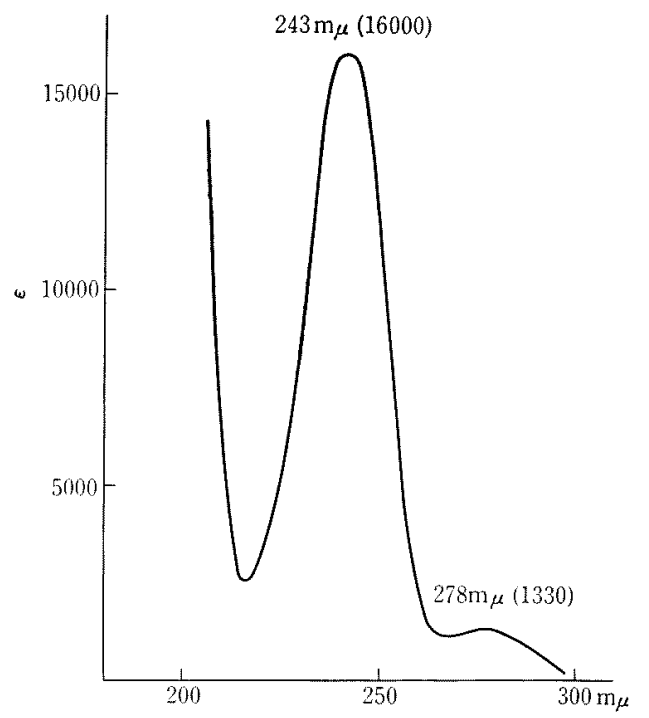

FIG. 3. UV Spectrum of the Product from Biphenyl.

was carried out as shown in Fig. 2.

The crude extract was developed on thinlayer chromatography. Bromcresolgreen positive, 2,4-dinitrophenylhydrazine positive and UV absorbing spot of $R f=0.83$ was detected. The spot of $R f=0.83$ was extracted with ether. Then the extraction was condensed in vacuo and crude crystals were obtained. The crude crystals were recrystalized in benzene and $n$-hexane-benzene.

The crystal was pale yellow plate and melted at $130^{\circ} \mathrm{C} \sim 131^{\circ} \mathrm{C}$. Elementary analysis gave $\mathrm{C} ; 68.55 \%, \mathrm{H} ; 6.21 \%, \mathrm{O} ; 25.24 \%$. And the

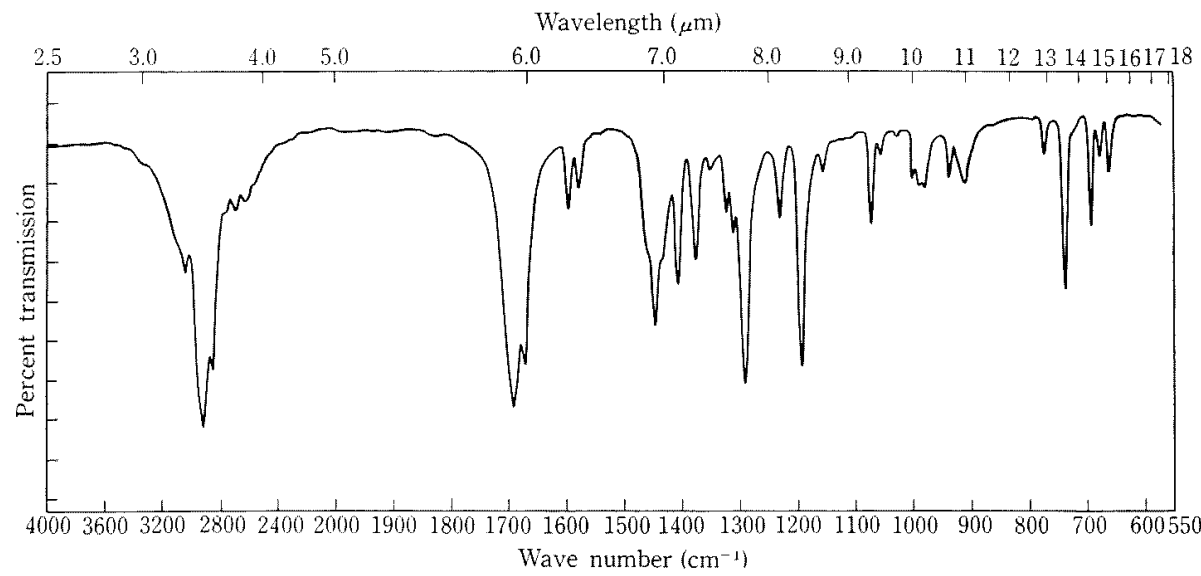

FIG. 4. IR Spectrum of the Product Obtained from the Culture Broth of S-291-B-1 Strain in Biphenyl Medium. 


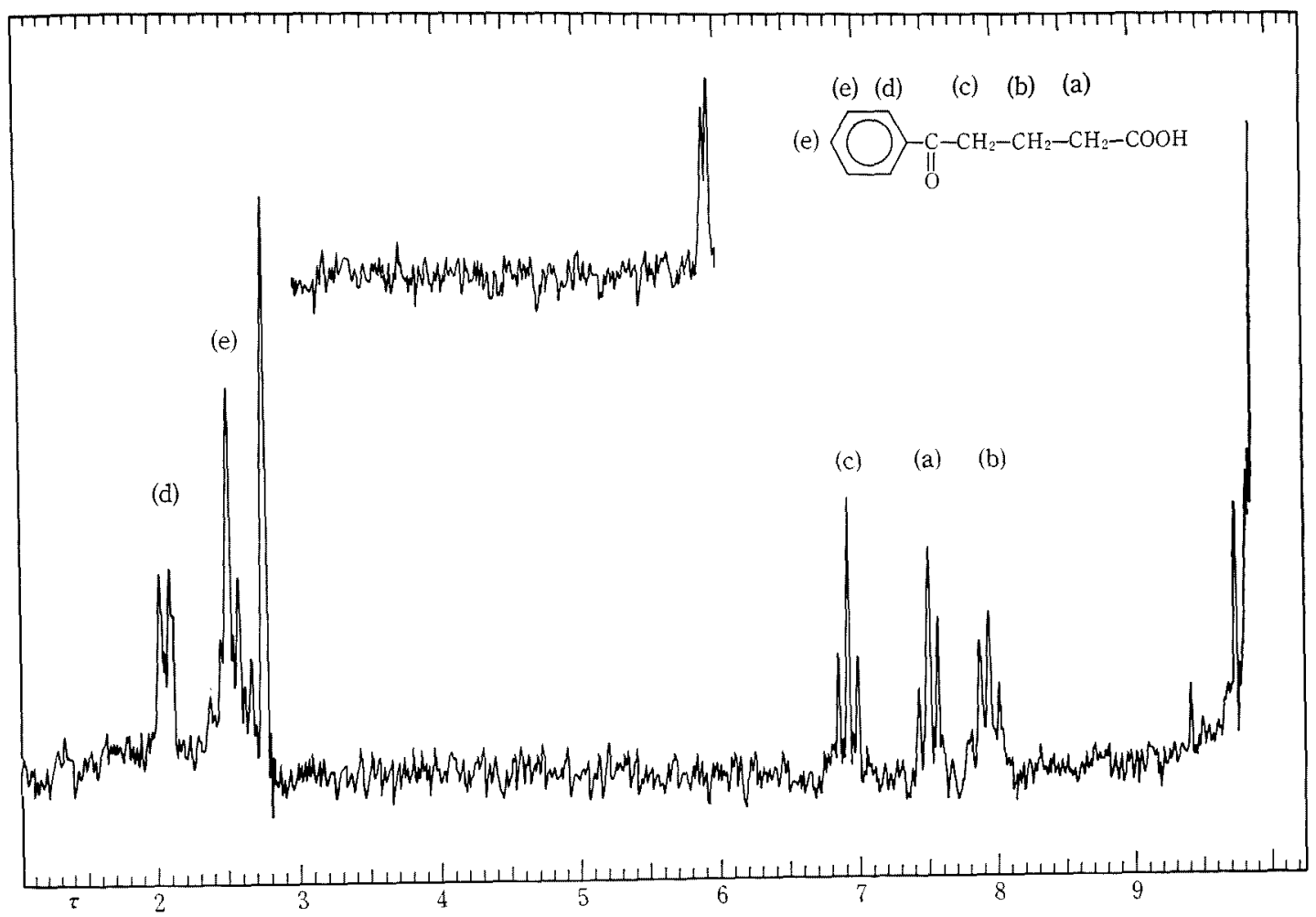

FIG. 5. NMR Spectrum of the Product from Biphenyl by S-291-B-1.

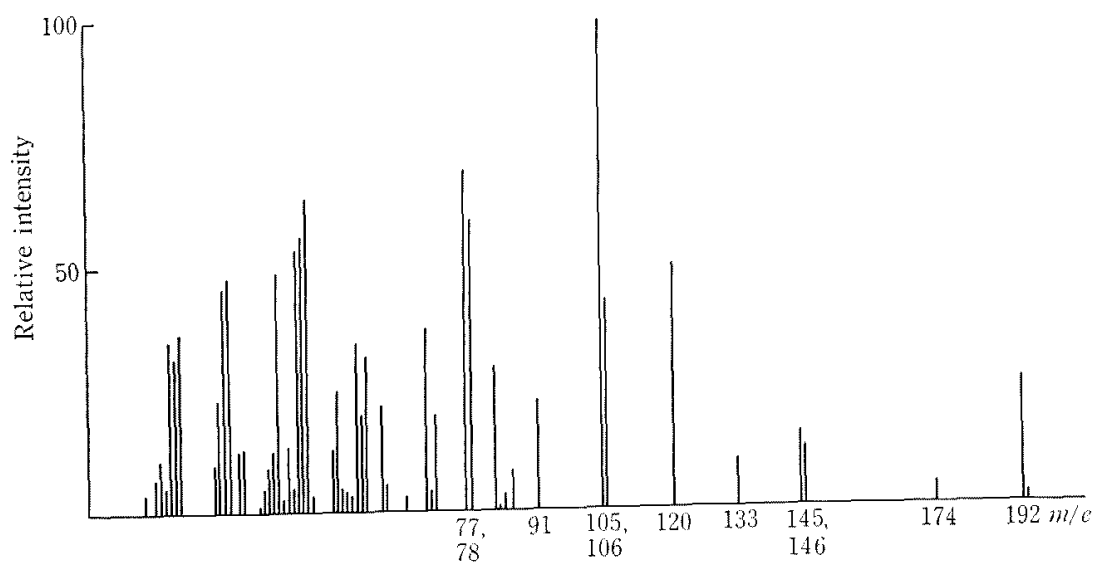

FIG. 6. MS Spectrum of the Product from Biphenyl.

calculated value of $\mathrm{C}_{11} \mathrm{H}_{12} \mathrm{O}_{3}$ were $\mathrm{C} ; 68.75 \%$, $\mathrm{H} ; 6.25 \%, \mathrm{O} ; 25.00 \%$.

UV $\lambda_{\max }^{\mathrm{EtoH}} \operatorname{m} \mu(\varepsilon): 242(16,000), 278(1,330)$, $\mathrm{IR} \nu_{\max }^{\mathrm{NujoI}} \mathrm{cm}^{-1}: 740(\mathrm{C}-\mathrm{H}), 1580(\mathrm{C}-\mathrm{C}), 1600$ $(\mathrm{C}=\mathrm{C}), 1680(\mathrm{C}=\mathrm{O}), 1695(\mathrm{C}=\mathrm{O}), \mathrm{NMR} \tau_{\mathrm{Me} \mathrm{Si}_{1}}^{\mathrm{CDCls}}$ : 7.92 (2H triplet $\left.\mathrm{CH}_{2}-\mathrm{CH}_{2}-\mathrm{CH}_{2}\right), 7.50(2 \mathrm{H}$ triplet $\left.\mathrm{CH}_{2}=\mathrm{COOH}\right), 6.92\left(2 \mathrm{H} \phi-\mathrm{CO}-\mathrm{CH}_{2}\right)$,
2.50 ( $\mathrm{H}$ doublet $\mathrm{C}_{8} \mathrm{H}_{5}-m-, p$-proton), 2.05 (H doublet $\mathrm{C}_{6} \mathrm{H}_{5}$-o-proton). MS m/e: 192 $\left(\mathrm{M}^{+}\right)$. These spectra are shown in Figs. 3, 4, 5 and 6 . The IR spectrum shows aromatic keto acid, that is, the absorbtions at $1670 \mathrm{~cm}^{-1}$, $1600 \mathrm{~cm}^{-1}, 1580 \mathrm{~cm}^{-1}$ and $740 \mathrm{~cm}^{-1}$ seem to indicate carbonyl conjugates with benzene 


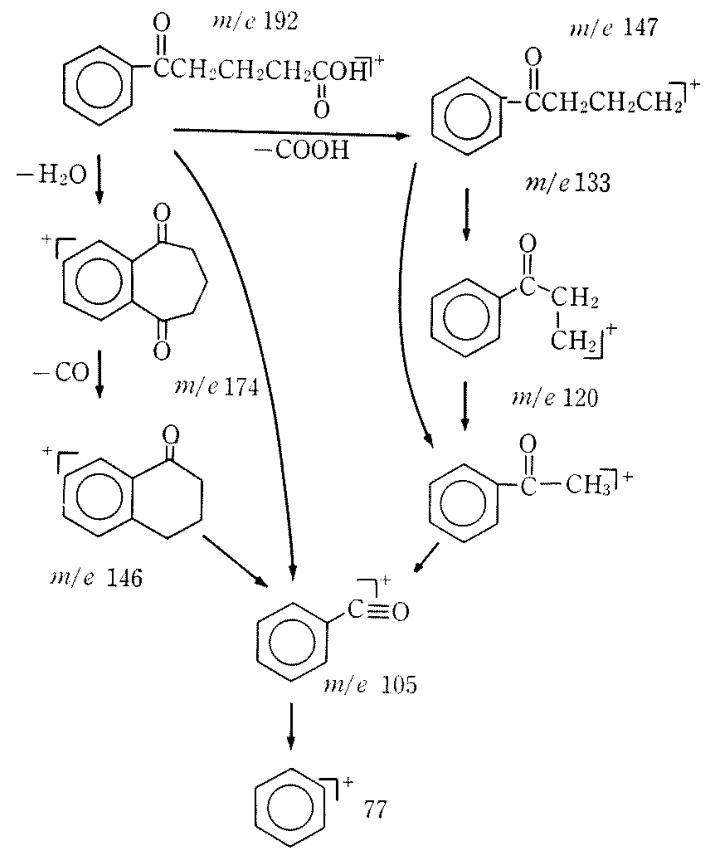

FIG. 7. The Fragmentation of $\gamma$-Benzoylbutyric Acid Considered.

$$
\begin{array}{rr}
\text { meta stable. M* } & 57.4(192 \rightarrow 105) \\
& 75.5(146 \rightarrow 105) \\
91.9(120 \rightarrow 105) \\
157.7(192 \rightarrow 174)
\end{array}
$$

ring, and the absorbtion at 1695 and the broad one from $2500 \mathrm{~cm}^{-1}$ to $2700 \mathrm{~cm}^{-1}$ indicate free carboxylic acid. The UV spectrum coincides with the IR absorbtion indicating benzoyl group.

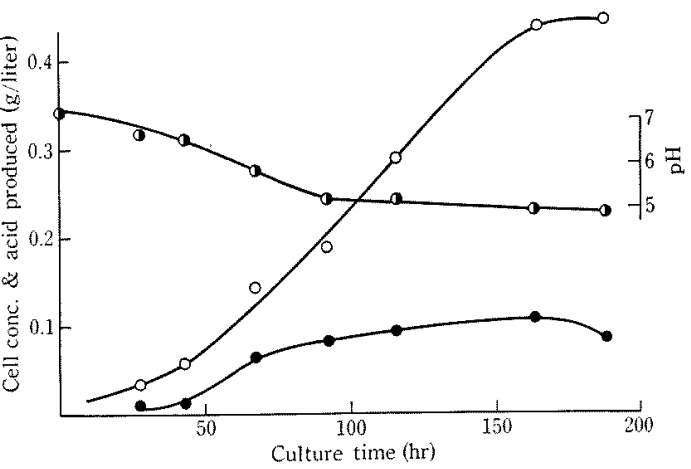

FIG. 8. Time Course of S-291-B-1 Cultured in Biphenyl Medium.

The culture medium was the same as the screening medium described in Materials and Methods.

-; Cell concentration, $O$; Acid produced, $\mathbf{0}$;

Therefore the structure of the product was considered to be $\gamma$-benzoylbutyric acid, which is shown in Fig. 5. And the fragmentation found in MS was very identical to the structure proposed from Fig. 7. The product was determined to be $\gamma$-benzoylbutyric acid.

Growth curve and $\gamma$-benzoylbutyric acid production

The time course of cell growth and acid production of S-291-B-1 on biphenyl of $5 \mathrm{~g} /$ liter was pursued in the screening medium. The growth curve, acid production and change of $\mathrm{pH}$ are given in Fig. 8. The amount of acid produced reached up to $0.42 \mathrm{~g} /$ liter.

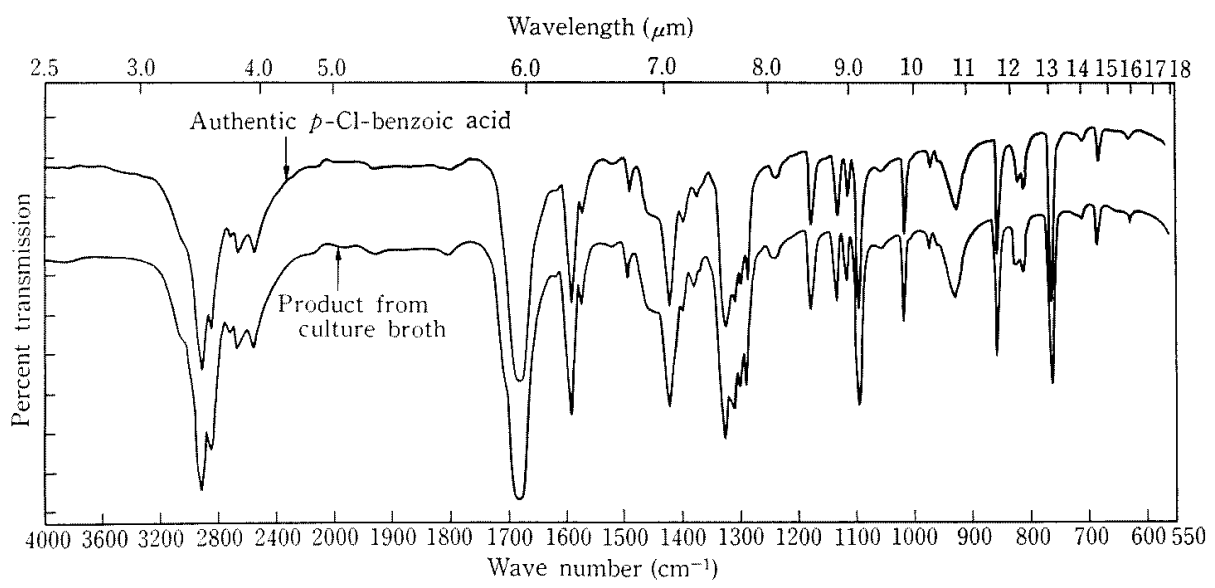

FIG. 9. IR Spectrum of the Product Obtained from Culture Broth of S-105-B-1 in $p$-Cl-Biphenyl Medium. 
Table III. Specificity of Substrate Assimilation and Product Accumulation

\begin{tabular}{cccc}
\hline Strain No. & \multicolumn{2}{c}{ Substrate } & Product \\
\hline S-105-B-1 & biphenyl & $p$-Cl-biphenyl & $p$-Cl-benzoic acid \\
S-267-B-1 & biphenyl & $p$-Cl-biphenyl & $p$-Cl-benzoic acid \\
& & & $\gamma$-benzoylbutyric acid \\
S-291-B-1 & biphenyl & $p$-Cl-benzoic acid \\
S-334-B-1 & biphenyl & $p$-Cl-biphenyl & $\gamma$-benzoylbutyric acid \\
& & $p$-Cl-biphenyl & - \\
\hline
\end{tabular}

The maximum cell growth was $1.1 \mathrm{~g} /$ liter after $187 \mathrm{hr}$ cultivation. The $\mathrm{pH}$ value of the culture broth moved downward with the acid production and showed 4.8 at the lowest.

The thin-layer chromatography of crude extracts of culture broth at each cultivation time were carried out, and through the cultivation only one spot was detected by spraying agents described before.

\section{The metabolic product from p-Cl-biphenyl}

Strain S-267-B-1 and S-105-B-1, obtained from the screening on biphenyl medium were cultured using $p$-Cl-biphenyl as a sole source of carbon in 5 liter Erlenmeyer flask with 1 liter liquid medium. After the cultivation, the acidic product was extracted and condensed as usual.

A large amount of crude crystals were obtained and the recrystallization was carried out in ethyl acetate. The crystal was white needle and sublimated at $163^{\circ} \mathrm{C} \sim 165^{\circ} \mathrm{C}$.

The IR spectrum of it was identical to authentic $p$-Cl-benzoic acid as shown in Fig. 9. The yield of $p$-Cl-benzoic acid from $p$-Clbiphenyl was more than $90 \%$ of the theoretical yield. Strain S-291-B-1 also produced $p$-Clbenzoic acid from $p$-Cl-biphenyl, but yield was very low.

\section{DISCUSSION}

As was mentioned before, substrates used in this experiment are organic synthesized materials. So it is very interesting whether microorganisms utilize these substrates or not. As the result of the investigation, the microbial degradation of polyphenyl and polyphenylrelated compounds was not so strange as shown in Tables I and II.

Some of these microorganisms were found to accumulate a large amount of aromatic carboxylic acid as the result of substrate degradation. For example $\gamma$-benzoylbutyric acid was accumulated in the culture broth with biphenyl medium and $p$-Cl-benzoic acid was produced from $p$-Cl-biphenyl in good yield. The specificity of substrate assimilation and product accumulation are listed in Table III. The metabolic pathway of these compounds in microorganisms appeared to be very similar.

As the application of these microorganisms or microbial product, biological activity of the degradation product of substrates were tested, and weak herbicidal activity of $\gamma$ benzoylbutyric acid against Chenopodium ficifolium was found.

On the other hand the degradation of these polyphenyl and polyphenyl-related hydrocarbons may be applied to the control of the environmental pollution. Some of these microorganisms might be expected to decompose P.C.B. (polychlo biphenyl).

And microbial conversion of other substrate used in this experiment are under investigation.

\section{REFERENCES}

1) T. Ohmori, S. Horiguchi and K. Yamada, Agr. Biol. Chem., 31, 1337 (1967).

2) T. Ohmori and K. Yamada, ibid., 33, 979 (1967).

3) T. Ohmori and K. Yamada, ibid., 34, 664 (1970).

4) T. Ohmori and K. Yamada, ibid., 34, 664 (1970).

5) D. Lunt and W. C. Evans, Biochem. J., 118, 54 (1970).

6) D. Catelani, G. Mosselmans, J. Nienhaus, C. Sorlini and V. Treccani, Experientia, 26, 922 (1970). 